\title{
An Improved Distribution Network Evaluation Index System
}

\author{
Ruiguo Liu and Kaijun Zhao* \\ Shandong University of Science and Technology, Taian 271000, P. R. China \\ ${ }^{*}$ Corresponding author
}

\begin{abstract}
At present, the comprehensive index evaluation system of distribution network does not include access to distributed power and electric heating, which is not in line with the actual situation nowadays. To this end, an improved comprehensive index evaluation system is proposed, and the weight of indicators is calculated by AHP. The evaluation criteria are processed by curve fitting method to get the index scoring function, so as to form a comprehensive index evaluation of the distribution network which can be more practical system.
\end{abstract}

Keywords-comprehensive evaluation index system; electric heating; distributed generation; analytic hierarchy process

\section{INTRODUCTION}

With the development of the times, people have more and more demand for electricity and higher and higher requirements. Therefore, it is very important to develop the distribution network. In order to achieve better development of distribution network, it is very important to establish a scientific and rational distribution network evaluation system.

In recent years, research on distribution network evaluation has yielded some achievements. Liu Rui et al. Established the comprehensive index evaluation system and the calculation method of each index from the aspects of economy, reliability and safety. The analytic hierarchy process was used to obtain the weight of each index, and finally the comprehensive evaluation was carried out. Mary and others from the grid performance, economic efficiency, social benefits in three aspects to establish a distribution network planning evaluation index system.

However, there is a problem that does not involve the distribution network access to distributed power and after heating the power distribution network and its indicators, ignoring the actual situation, this paper presents an improved distribution network evaluation index system.

\section{ACCESS TO DistribUted GENERATION AND ELECTRIC HEATING}

\section{A. Influence on the Reliability of Power Supply}

As a power supply to power outage users, distributed power can greatly reduce the average power outage time of users. But in the analysis of the influence of distributed power supply on power supply reliability, the formation of the isolated island and the randomness of the output power of the distributed power supply should be taken into account. When the power supply capacity of the power grid is sufficient and the distribution network planning island can't be formed, the access of the distributed power supply will not have a positive impact on the reliability of the distribution network. When the power supply capacity of the power grid is insufficient and the distribution network is planned to form a solitary island. If the distributed power is located in the planned islanding, the distributed power will transmit power to the isolated island, and the output of the distributed power will improve the power supply reliability of the distribution network. If the distributed power is not in the planned Island, it has no effect on the reliability.

\section{B. Influence on Line Loss Rate}

The template is used to format your paper and style the text. All margins, column widths, line spaces, and text fonts are prescribed; please do not alter them. You may note peculiarities. For example, the head margin in this template measures proportionately more than is customary. This measurement and others are deliberate, using specifications that anticipate your paper as one part of the entire proceedings, and not as an independent document. Please do not revise any of the current designations.

\section{Influence of Short Circuit Current Level}

When the system fails, the access to the distributed power supply will provide short circuit current to the fault point. The three access modes of distributed power supply include: 1) low voltage access 2 ) medium voltage access 3 ) special line access.

The calculation shows that the distributed power is if the medium voltage mode is used in the distributed power supply, the short circuit current of the distribution network has little influence. If the distributed power is connected by dedicated line mode, the short circuit current supplied by the distributed power will reach more than $3 \mathrm{kA}$. So the capacity must be connected to the distributed power supply to limit it.

\section{Influence on the Load Rate}

When the load rate of the distribution network is analyzed, the margin and carrying capacity of the grid transmission and transformation equipment during the winter heating period are analyzed, according to the operation conditions of the grid and the load characteristics of different regions. By analyzing the distribution network of electric heating, the seasonal load fluctuation is comparatively large. In winter, with the use of 
some electric heating equipment, the load increases obviously. During the Spring Festival, the load reached the peak of the annual power consumption, causing serious overload of distribution transformers and lines. In summer, the population of electric heating is less and the electricity consumption is relatively less.

\section{COMPREHENSIVE EVALUATION INDEX SYSTEM OF DISTRIBUTION NETWORK}

The establishment of a comprehensive evaluation system of distribution network consists of 3 steps:

1) The four indicators are selected to include security, economy, reliability and technology. The comprehensive evaluation index system of distribution network is established by considering the influence of distribution network including distributed power supply and electric heating on the distribution network itself and its indexes. As shown in Figure I, Figure II, Figure III, Figure IV, and Figure V.

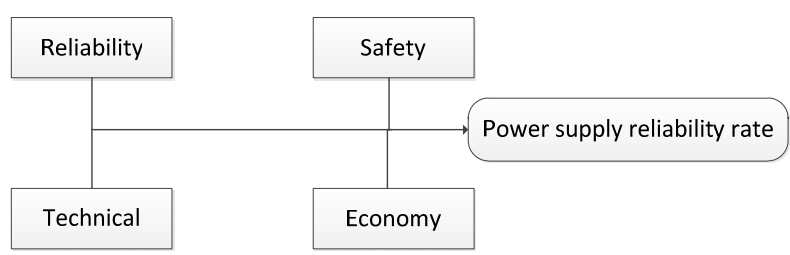

FIGURE I. FACTORS INFLUENCES ON POWER SUPPLY RELIABILITY RATE

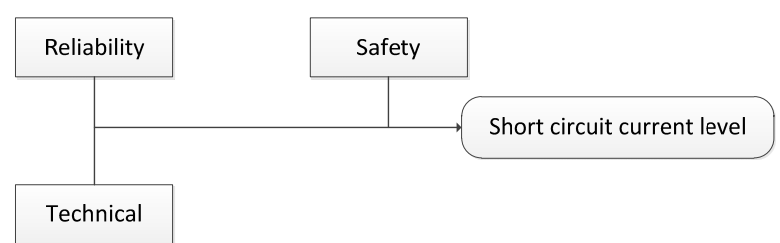

FIGURE II. FACTORS INFLUENCES ON SHORT CIRCUIT CURRENT LEVEL

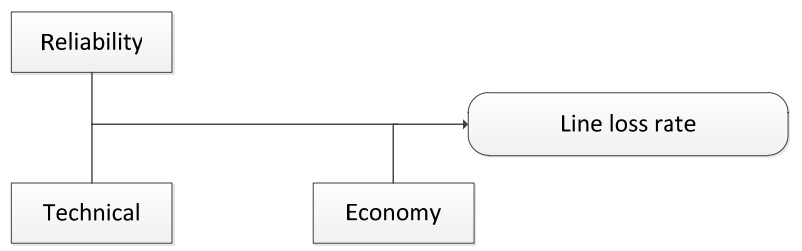

FIGURE III. FACTORS INFLUENCES ON LINE LOSS RATE

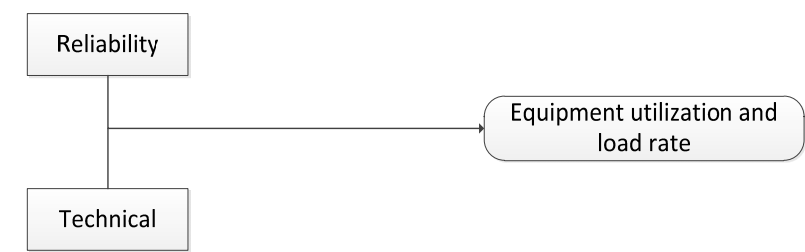

FIGURE IV. FACTORS INFLUENCES ON EQUIPMENT UTILIZATION AND LOAD RATE

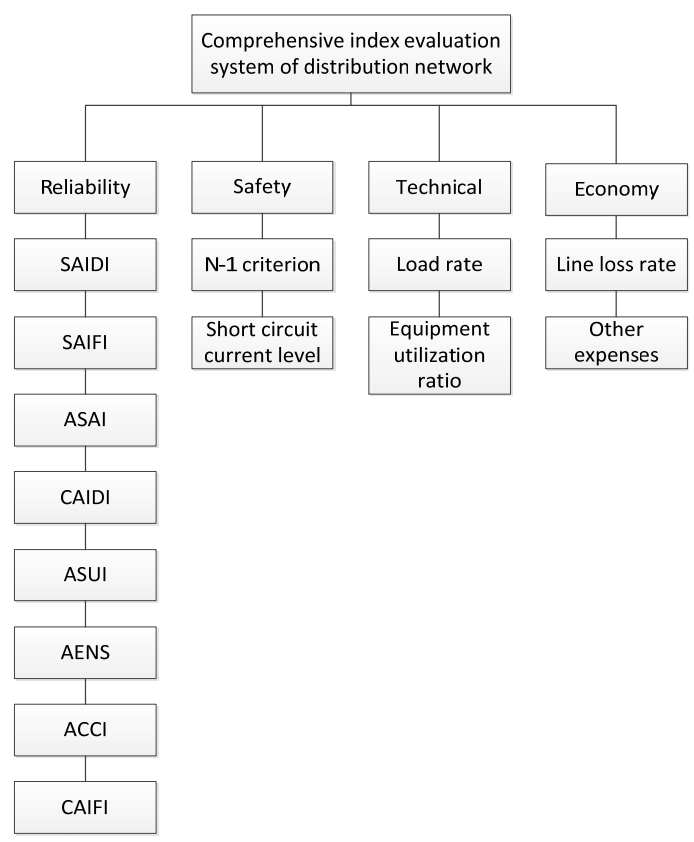

FIGURE V. COMPREHENSIVE EVALUATION INDEX SYSTEM OF DISTRIBUTION NETWORK

2) The analytic hierarchy process is used to calculate the weight of the index.

3) The index evaluation function is used to evaluate the index by setting index evaluation criterion.

\section{INDEX WEIGHT AND SCORING STANDARD}

1) Index weight

The setting of indicator weight is an important link in the comprehensive evaluation. In this paper, the analytic hierarchy process and the matlab calculation tools are used to determine the weight of each indicator simply and conveniently. The results, of which, in the overall evaluation system reliability of the weight of 0.3 , followed by the second-level indicators for the index relative to the first-class indicators of the weight.

As can be seen from Table I, in the reliability index, the system average duration of power outage is of the utmost importance. Meanwhile, the average power outage frequency of the system and the duration of the average outage of users are also important, and the average system availability is relatively low.

TABLE I. PART OF INDEX WEIGHT

\begin{tabular}{|c|c|}
\hline Two level index & $\begin{array}{c}\text { Weight in the general } \\
\text { evaluation system }\end{array}$ \\
\hline SAIDI(0.18) & 0.054 \\
\hline SAIFI(0.16) & 0.048 \\
\hline ASAI(0.13) & 0.039 \\
\hline CAIDI(0.16) & 0.048 \\
\hline ASUI(0.12) & 0.036 \\
\hline AENS(0.09) & 0.027 \\
\hline CAIFI(0.07) & 0.021 \\
\hline ACCI(0.09) & 0.027 \\
\hline
\end{tabular}

2) Index scoring standard 
The impact of the evaluation criteria on the final results is crucial. Through the score, the advantages and disadvantages of different distribution networks can be compared intuitively, the criteria such as "excellent, good and passing" can't be used to measure them. At the same time, with the development of distribution network, many indicators will be more and more difficult to improve, and the improvement of every point will increase more and more. Therefore, the setting of evaluation criteria should reflect this characteristic.

This paper uses the analytic hierarchy process to set up the construction characteristics of the index criteria. But the evaluation criterion can not reflect the change of the index score well, and it is easy to make the difference between the different indexes not ideal. Therefore, this paper uses the curve fitting method to deal with the evaluation criterion, and obtains the smoothed scoring function. As shown in Table II, in which $\mathrm{x}$ represents the index value, $\mathrm{y}$ represents the score.

TABLE II. PART OF INDEX SCORE FUNCTION

\begin{tabular}{|c|c|}
\hline Two level index & Scoring function \\
\hline SAIDI(0.18) & $y=53.87 x^{2}+46.13 x$ \\
\hline SAIFI(0.16) & $y=112.2 x^{2}-214.76 x+100$ \\
\hline ASAI(0.13) & $y=-108.6 x^{2}+208.6 x$ \\
\hline CAIDI(0.16) & $y=112.2 x^{2}-214.76 x+100$ \\
\hline
\end{tabular}

According to the score function given in Table II, the secondary indicators index of the evaluation object can be calculated, and then the overall score of each distribution network can be calculated upward according to the AHP.

$$
S^{k}=\sum_{j=1}^{n} S_{j}^{(\mathrm{k}+1)} W_{j}^{(\mathrm{k}+1)}
$$

Where $S^{(k)}$ is the score of an indicator $A^{(\mathrm{k})}$ at the $\mathrm{k}$ level of the hierarchy, $\mathrm{j}$ is the number of $\mathrm{k}+1$ level indicators of the indicator $A^{(\mathrm{k})}$, and $S_{j}^{(\mathrm{k}+1)}$ is the score of the $\mathrm{k}+1$ level indicator $\mathrm{j}$ of the indicator $A^{(\mathrm{k})}: W_{j}^{(\mathrm{k}+1)}$ is Sub-index j weight.

\section{CASE STUdY}

This paper selects the distribution network of three cities as the evaluation object to conduct an actual evaluation analysis to verify the practicality of the evaluation system, three cities were set as $\mathrm{x}, \mathrm{y}, \mathrm{z}$, some of the indicators of the basic data shown in Table III.

TABLE III. PART OF BASE INDEX DATE OF EVALUATION OBJECTS

\begin{tabular}{|c|c|c|c|c|}
\hline City & SAIFI & CAIDI & SAIDI & ASAI \\
\hline $\mathrm{x}$ & 0.18 & 0.11 & 0.83 & 0.67 \\
\hline $\mathrm{y}$ & 0.23 & 0.36 & 0.41 & 0.15 \\
\hline $\mathrm{z}$ & 0.19 & 0.50 & 0.60 & 0.55 \\
\hline
\end{tabular}

According to Table I data can be calculated at all levels of indicators of the score, with reliability as an example, three city distribution network score shown in Table IV.

TABLE IV. NETWORK STRUCTURE LEVEL SCORE OF THREE URBAN DISTRIBUTION NETWORKS

\begin{tabular}{|c|c|c|c|}
\hline $\begin{array}{c}\text { Secondary } \\
\text { indicators }\end{array}$ & $\begin{array}{c}\text { The score } \\
\text { of } \mathbf{x}\end{array}$ & $\begin{array}{c}\text { The score } \\
\text { of } \mathbf{y}\end{array}$ & $\begin{array}{c}\text { The score } \\
\text { of } \mathbf{z}\end{array}$ \\
\hline SAIFI & 65.0 & 56.5 & 63.2 \\
\hline CAIDI & 77.7 & 37.2 & 20.7 \\
\hline SAIDI & 75.4 & 28.0 & 47.1 \\
\hline ASAI & 91.0 & 28.8 & 81.9 \\
\hline
\end{tabular}

The final three cities and the total score of the first grade index score results shown in Table V.

Table $\mathrm{V}$ shows that the comprehensive evaluation results can clearly reflect the overall development of the distribution network in various cities, the results also meet the basic positioning of each city. Although the total score of $\mathrm{x}$ cities is higher than that of $\mathrm{y}$ and $\mathrm{z}$ prefectures, the cost of $\mathrm{x}$ distribution network in cities is too poor and should be strengthened in this respect. However, the economic benefits of the urban distribution network and the safety of the urban distribution network are its advantages and need to be improved in other aspects.

Through the concrete analysis and horizontal comparison of secondary indicators, we can also find out the weak points of each city's distribution network, make corresponding construction and improvement, and make the distribution network construction more targeted through the above analysis. Lay the foundation for future construction planning.

TABLE V. COMPREHENSIVE EVALUATION SCORE OF THREE URBAN DISTRIBUTION NETWORKS

\begin{tabular}{|c|c|c|c|c|c|}
\hline $\begin{array}{c}\text { first } \\
\text { indicators }\end{array}$ & $\begin{array}{c}\text { The score of } \\
\text { reliability }\end{array}$ & $\begin{array}{c}\text { The score of } \\
\text { economic }\end{array}$ & $\begin{array}{c}\text { The score of } \\
\text { technical }\end{array}$ & $\begin{array}{c}\text { The score of } \\
\text { safety }\end{array}$ & $\begin{array}{c}\text { Total } \\
\text { Score }\end{array}$ \\
\hline $\mathrm{X}$ & 80.1 & 26.8 & 71.0 & 83.8 & 65.4 \\
\hline $\mathrm{y}$ & 59.0 & 56.0 & 58.6 & 80.9 & 63.6 \\
\hline $\mathrm{z}$ & 54.9 & 15.9 & 45.5 & 89.6 & 51.5 \\
\hline
\end{tabular}

\section{SUMMARY}

In this paper, a comprehensive evaluation system of distribution network is proposed, which includes distributed generation and electric heating. The system not only can fully display all aspects of distribution network, but also can achieve the continuity of index score through curve fitting. There are many shortcomings in this paper. With the further study of distribution network, some parts are added and refined on the basis of this evaluation system, which can further improve the comprehensive index evaluation system of distribution network.

\section{REFERENCES}

[1] Ziari I, Ledwich G, Ghosh A, et al. Optimal distribution network reinforcement considering load growth, line loss, and reliability[J]. IEEE Transactions on Power Systems, 2013, 28(2): 587-597. 
[2] $\mathrm{Xu} \mathrm{Y,} \mathrm{Singh} \mathrm{C.} \mathrm{Distribution} \mathrm{systems} \mathrm{reliability} \mathrm{and} \mathrm{economic}$ improvement with different electric energy storage control strategies[C]//Power and Energy Society General Meeting, 2011 IEEE. IEEE, 2011: 1-8.

[3] Chuansheng X, Dapeng D, Shengping H, et al. Safety Evaluation of Smart Grid based onAHP-Entropy Method[J]. Systems Engineering Procedia. 2012: 203-209.

[4] Atwa Y M, El-Saadany E F, Guise A C. Supply Adequacy Assessment of Distribution System Including Wind-Based DG During Different Modes of Operation[J]. IEEE Transactions on Power Systems, 2010, 25(1):78-86.

[5] Mcgranaghan M, Goodman F. Technical and system requirements for Advanced Distribution Automation[C]// International Conference and Exhibition on Electricity Distribution. IET, 2010:1-5. 